\title{
Thermal Analysis of Coffee Hulls and their Effect on the Drying Process in Conventional Ovens
}

\author{
Milton Javier Muñoz Neira, Manuel Roa and Rodrigo Correa* \\ Universidad Industrial de Santander - UIS Colombia, Santander, Colombia; \\ milton2178736@correo.uis.edu.co,mafrara5@yahoo.es, \\ crcorrea@saber.uis.edu.co
}

\begin{abstract}
Background/Objectives: This article includes some of the most relevant experimental results related to the thermal properties of coffee hulls taken from samples of a Colombian coffee variety Castilla. Methods: Coffee hull samples were analyzed using IR, DSC, TGA and DTGA. Analytical thermal experiments described its thermal behavior when it was heated at $5^{\circ} \mathrm{C} / \mathrm{min}$ from room temperature to about $900^{\circ} \mathrm{C}$. Furthermore, we include some drying curves and analyze the observed delay effect of the hull presence on the coffee drying process. Findings: Some of the main thermal transitions where observed in the range of $50-300^{\circ} \mathrm{C}$. The IR test showed that its main composition was cellulose. Such delay was related to the hull composition. The diffusion coefficients of water in coffee grains with hull, without its hull, and of hull alone, are also reported. Applications: This work provides important information to understand in a better form some thermal characteristics and inference in drying process of coffee grains hull of variety Castilla, original from Colombia northeast region.
\end{abstract}

Keywords: Coffee Grains Drying, Coffee Hull, Thermal Analysis, DSC, TGA, IR

\section{Introduction}

Coffee is one of the most representative products of agriculture in Colombia. Data from the Ministry of Agriculture show that, on average, over the past five years, coffee has contributed $12.74 \%$ to the gross domestic product of the agricultural sector. For its part, the Ministry of Finance of Colombia estimated for 2017, a production of 14.19 million bags of coffee of $60 \mathrm{~kg}$ each, which ranked the country as the third largest producer in the world. This large production represents, on the other hand, a high generation of solid waste, among which, those associated with the natural envelope of the grain are the most representative. Figure 1 shows the different parts that must be removed from the grain in the benefit stage made by wet way, and that become solid waste, i.e., outer skin, pulp, mucilage, hull and silver skin. In ${ }^{1}$ refer for this case that for each ton of coffee treated in the benefit, 0.18 tons of solid waste associated with its wrapping are generated, of which approximately $12 \%$ correspond to its shell (mixture of skin, pulp and grain hullor parchment).

The handling of the hull as a residual product of the coffee process is consequently substantial. At the time, it is important to know the effect that this coverage has on the grain drying process. When the coffee is processed by wet process, the grains are dried together with their hull (parchment coffee) both artisanal (spreading it on the floor and drying it with the sun and air) or by a conventional dryer, removing it prior to the time of roasting. This removal is done manually in order to avoid mechanical damage to the coffee grain. This is due to the fact that the removal of the endocarp (hull) is difficult before drying due to the high degree of humidity in the grain (around 53\%). In addition to this, the hull protects

${ }^{*}$ Author for correspondence 


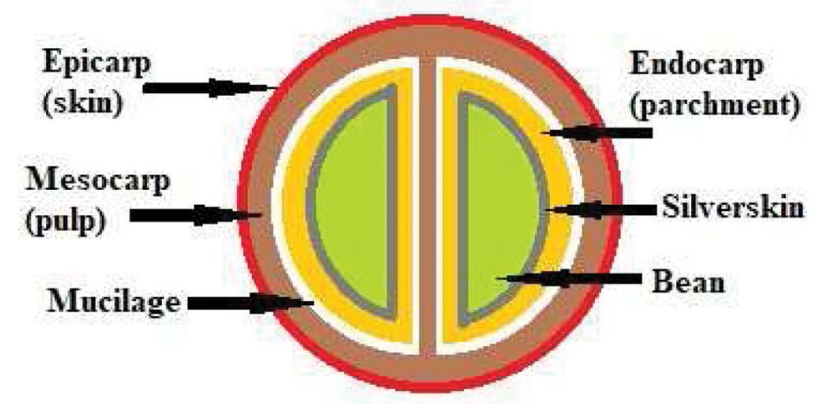

Figure 1. A typical structure of a coffee grain.

the grain during drying, and after this, in the transport process (before storage for roasting), of lacerations that may favor oxidation processes thereof, a situation that would significantly deteriorate its quality.

Various studies detail the properties and uses of coffee hulls. $\mathrm{In}^{2}$, based on data reported by ${ }^{3}$, highlights the high fiber content in coffee hulls (62.1\%) and cellulose (46.1\%). Both reports, however, rule out its possible use as animal feed, due to its low nitrogen content $(0.39 \%)$ and the presence of components such as lignin (24.4\%), but highlight instead its potential as fuel. In the same sense $^{4,5}$ are pronounced. The latter report a calorific value for the hull of $17.9 \mathrm{MJ} / \mathrm{kg}$, and a possible production of $227 \mathrm{~kg} / \mathrm{ha}$ per year.

On the other hand ${ }^{6}$, detail the composition of the hull, as consisting of cellulose (40-49\%), hemicellulose (25-32\%), lignin (33-35\%) and ash (0.5-1.0\%), based on data from ${ }^{7}$. The latter clarify the similarity of these percentages with those of wood, and propose the use of hulls for the manufacture of agglomerated boards. In another interesting work ${ }^{8}$ determined the proximal composition of three samples of coffee hull, after being dehydrated, which on average registered $5.33 \%$ humidity, $5.6 \%$ protein, $1.2 \%$ fat, $3.46 \%$ ash, $65.2 \%$ fiber raw and $19.2 \%$ nitrogen-free extract. In the same study, from the analysis of the relationship between the insoluble dietary fiber (edible parts of the plants but resistant to digestion and absorption in the human small intestine and with partial or complete fermentation in the large intestine, in whose composition include the polysaccharides, oligosaccharides, and lignin), with respect to the soluble dietary fiber, for the same samples, it is concluded that the coffee hull is not a good source of fiber for preparation of food rich in fiber.

$\mathrm{In}^{2}$ reported the thermogravimetric and thermogravimetric differential analysis (TGA and DTGA for its acronym in English) made to the coffee hull, with a heating rate of $40 \mathrm{~K} / \mathrm{min}$. In this, three areas of mass loss stand out: at less than $200^{\circ} \mathrm{C}$, in which water is evaporated and $\mathrm{CO}$ and $\mathrm{CO}_{2}$ are released, between 200 and $400^{\circ} \mathrm{C}$, with a mass loss of $44 \%$ and decomposition of cellulose and hemicellulose, and between 580 and $650^{\circ} \mathrm{C}$ with a loss of $34.86 \%$ and decomposition of lignin. The temperature for maximum decomposition was $300^{\circ} \mathrm{C}$. Other works are dedicated to the realization of analyzes on the complete shell of the grain (mixture of skin, pulp and grain hull). Without specifically detailing the hull ${ }^{10}$ made the TGA, DTGA and DSC analysis, to samples of internal shell (which contains hull and pulp), and external (containing skin and pulp). The results for the inner shell of $25 \mathrm{mg}$ samples analyzed at $10^{\circ} \mathrm{C} / \mathrm{min}$, reveal mass losses of $8.55 \%$ between 25 and $150^{\circ} \mathrm{C}, 51.20 \%$ between 150 and $400^{\circ} \mathrm{C}, 34.95 \%$ between 401 and $580^{\circ} \mathrm{C}, 2.08 \%$ between 581 and $901^{\circ} \mathrm{C}$, and $3.23 \%$ for temperatures above $900^{\circ} \mathrm{C}$. The mixed shell (internal and external) recorded an enthalpy variation of $249 \mathrm{~J} / \mathrm{g}$. A similar study by ${ }^{\underline{11}}$ recorded the onset of thermal degradation of the coffee shell at $200^{\circ} \mathrm{C}$. Alternate research on coffee shell is detailed in ${ }^{12}$, about the absorption of $\mathrm{Ni}$ (II) with the use of activated carbon, a study that shows a high affinity of this residue for said absorption. $\operatorname{In}^{\frac{13}{3}}$, it is proposed to use the fiber present in the coffee shell as reinforcement material for the manufacture of a thermoplastic compound (polyethylene). On the other hand ${ }^{14}$ describe the micro and nano cellulose present in the shell. Finally ${ }^{15}$, in a work on the characterization of lignin, and $\frac{16}{}$, analyze the manufacture of briquettes from the coffee shell, for use in combustion processes in domestic kitchens, among other proposed works.

This article describes the results of IR and thermal analysis of the coffee bean hull, while the effect of its presence on drying curves is discussed. In the following numerals, in addition to the thermal characterization performed, i.e., using IR, TGA, DTGA and DSC, the calculation of diffusion coefficients for the coffee grain drying process, with and without hull is presented. In the same way, the drying curve was made for the hull, in order to know its moisture absorption characteristics, and its diffusion coefficient in it.

\section{Materials and Methods}

To carry out the thermal analysis, a sample of hull of coffee beans variety Castilla was taken from a crop in 
the southeastern region of the department of Santander, Colombia, obtained from a depulped, fermented, washed and drained grain. TGA/DSC/DTGA tests were performed at a heating rate of $5^{\circ} \mathrm{C} / \mathrm{min}$. The tests were carried out in an inert atmosphere of nitrogen and with Infra-Red (IR) coupling of gases. The ASTM E1131-08 and ASTM E1269-11 standards were followed. On the other hand, for the study of drying, several samples of coffee of the same variety Castilla were used, coming from the same geographical region as the previous ones. Each sample consisted of approximately $63.5 \mathrm{~g}$ of coffee. The samples were hydrated with distilled water for a period of 48 hours. After this time, the fermented grains were also washed in distilled water, and left to rest for a time that varied between 20 and 30 minutes. This sequence simulated the daily process of fermentation and washing prior to the drying of the grain, in the treatment that is called "wet process" in a small-scale processing plant. In this way, three types of tests were carried out: one with grains that had hull, another with grains to which the hull was removed manually, and another with hull alone without the grain. Four repetitions were made for grains with hull and for grain without hull, and two repetitions for the hull alone. The results of the thermal analysis and the drying process are detailed below.

\section{Results}

In this section some of the IR and thermograms obtained for samples of coffee hull of the variety Castilla are shown. The hull was carefully removed from the coffee bean and placed in the sample holder for analysis without any pretreatment. TGA and DSC assays were also carried out, as discussed below.

\subsection{Analysis of the Coffee Hull by Infrared Spectroscopy}

Figure 2 shows the IR spectrum of the coffee hull, where mainly characteristic signals for cellulose derivatives are observed, such as: the $\mathrm{OH}$ group around $3300 \mathrm{~cm}^{-1}$, about $2900 \mathrm{~cm}^{-1}$ the signal of the $\mathrm{CH}$ bond, around $1700 \mathrm{~cm}^{-1}$ corresponding signal $\mathrm{H}-\mathrm{O}-\mathrm{H}$, around $1600 \mathrm{~cm}^{-1}$ signal corresponding to the carbonyl group $\mathrm{C}=\mathrm{O}$, about 1160

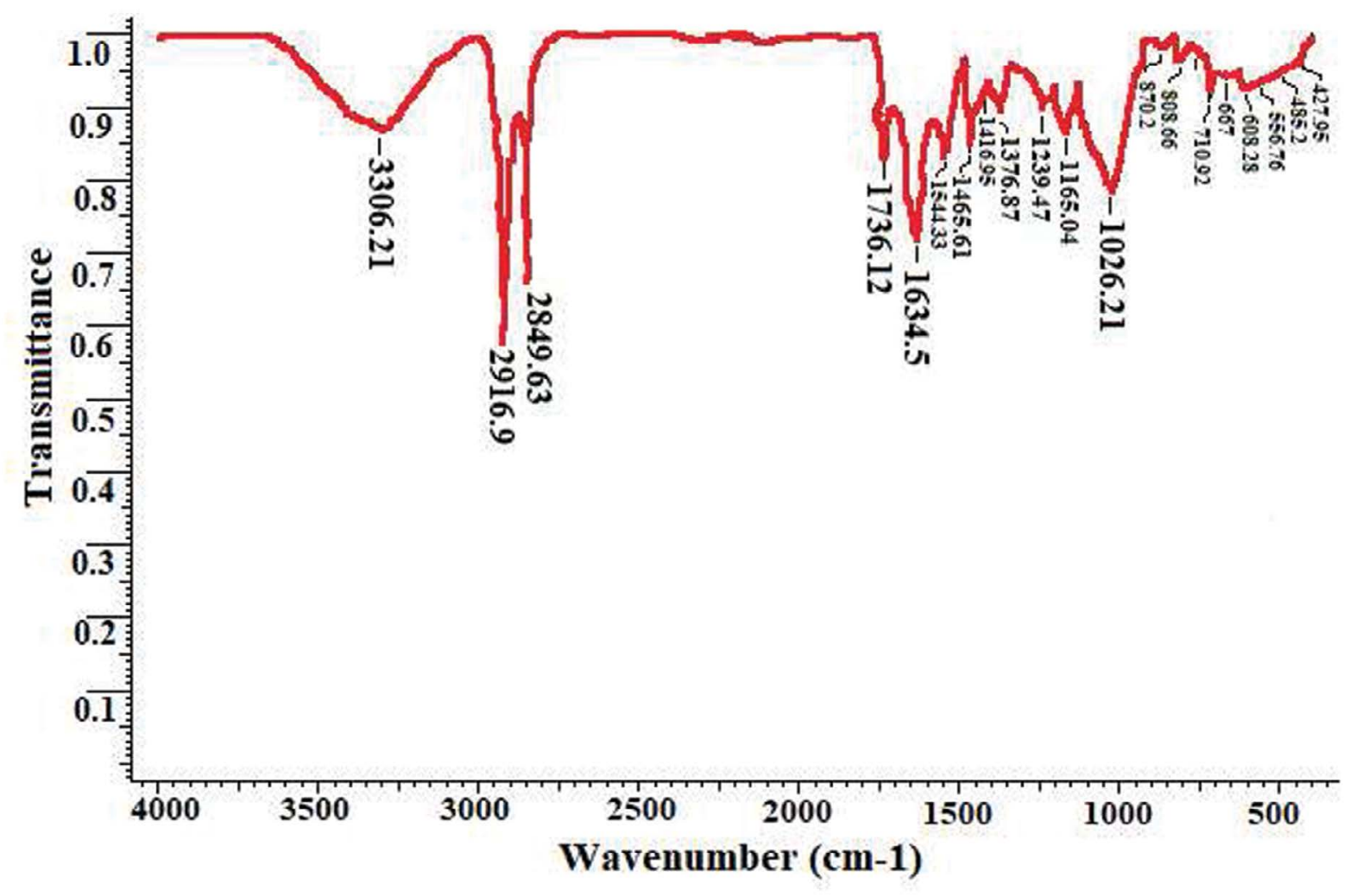

Figure 2. IR spectrum of coffee hull of grain variety Castilla. 
$\mathrm{cm}^{-1}$ signals of $\mathrm{CO}$ and $\mathrm{C}-\mathrm{O}-\mathrm{C}$. These signals allow concluding that the coffee hull is composed mainly of cellulose derivatives.

According to Beer's law, the concentration of an analyte is proportional to the absorbance of its characteristic signals. This principle allows detecting the appearance and disappearance of a component present in a mixture. Figure 3 gathers the set of infrared spectra obtained at each temperature of the thermogravimetric test of the coffee hull. Because it is a material and not a pure compound, each temperature generates a mixture of gases due to degradation, boiling and even molecular rearrangements. For this reason, the analysis of detailed signals to assign to a specific molecule is very complicated, given that some bands can overlap with others. For the present case we use Bruker's OPUS Software, and its databases of IR spectra, in order to identify possible components of the mixtures.

As it was mentioned, Beer's law defines that the concentration of molecule is proportional to the intensity of its signals, for this reason the first spectra obtained in the thermogravimetric test have very low absorbance or even no signals, because the initial temperatures do not allow the generation of gaseous products, or their quantities are very low.

Because, as shown in Figure 2, the major component of the hull is cellulose, its decomposition products will be present during a large part of the test and its signals will overlap those of lower concentration. This is why most of the spectra are very similar. The spectra were selected at $115^{\circ} \mathrm{C}$, $278^{\circ} \mathrm{C}$ and $472^{\circ} \mathrm{C}$ because they show marked variations and a good resolution. (Figures 4-6) the process of dehydration

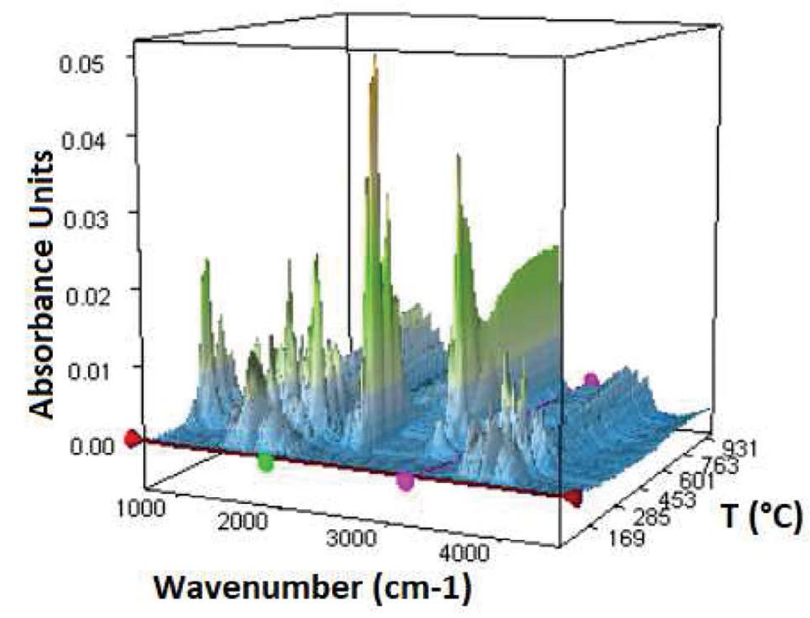

Figura 3. Spectrum 3D of a coffee hull sample at heating speed of $5^{\circ} \mathrm{C} / \mathrm{min}$. of the hull begins around $32^{\circ} \mathrm{C}$ and this process can get to about $200^{\circ} \mathrm{C}$. That is why it is observed in Figure 4 that the main component of the gas mixture is water.

Figure 5 shows the spectrum of the gaseous product mixture at $278^{\circ} \mathrm{C}$. It shows the formation of characteristic carbon dioxide signals, a product of the degradation of the large cellulose (organic) chains, as well as signals similar to naphthalene sulfonic acid, indicative of the presence of aromatic groups, carboxylic acids, and some heteroatoms as sulfur and nitrogen, present in some alkaloids and benzene derivatives of low concentration in the hull.

The gas mixture spectrum at $472^{\circ} \mathrm{C}$, as shown in Figure 6 , shows own signals of methane and cyclohexane, which are related to low molecular molecules corresponding

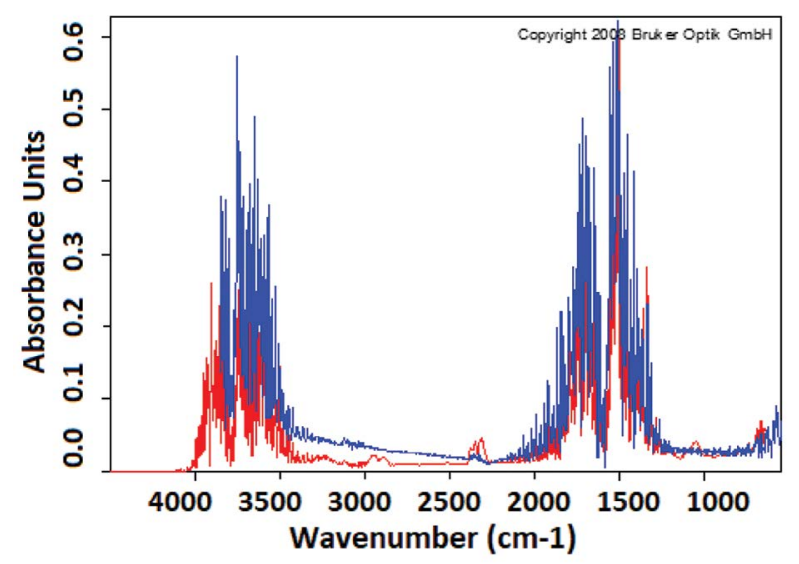

Figure 4. IR spectrum at $115^{\circ} \mathrm{C}-5^{\circ} \mathrm{C} / \mathrm{min}$ (red) and IR spectrum of water from Bruker data base (blue).

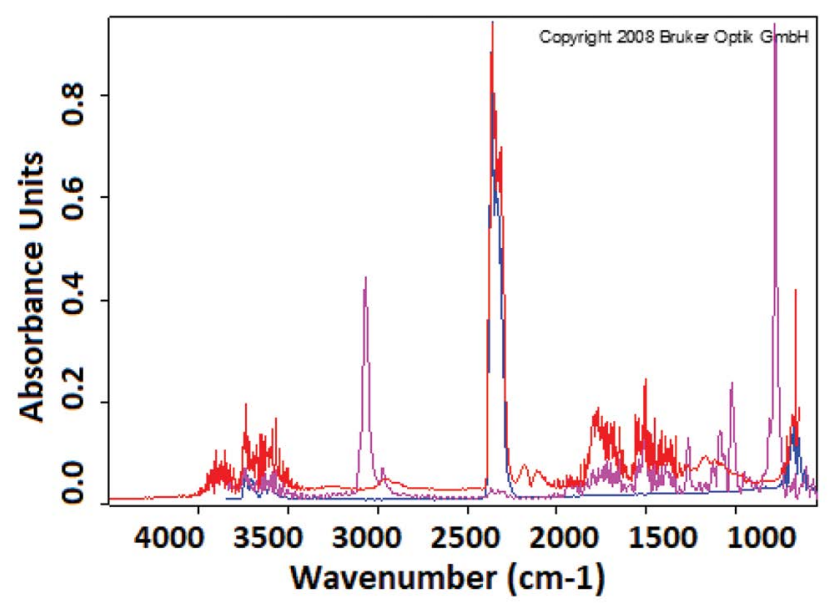

Figure 5. IR spectrum at $278^{\circ} \mathrm{C}-5^{\circ} \mathrm{C} / \mathrm{min}$ (red), spectrum of dioxide carbon from Bruker data base (blue) and IR spectrum of naphthalenesulfonic acid from Bruker data base too (purple). 
to the degradation of cellulose, which is the major component of the coffee hull.

\subsection{TGA and DSC Results}

Figure 7 shows the analysis of the thermogram of the hull of a coffee variety Castilla, at $5^{\circ} \mathrm{C} / \mathrm{min}$. In it, it is possible observe that different mass losses. Between $33^{\circ} \mathrm{C}$ and $33.7^{\circ} \mathrm{C}$ there is a loss of $11.49 \%$ corresponding to low molecular weight compounds and free water. In the range of $33.7^{\circ} \mathrm{C}$ to $251.2^{\circ} \mathrm{C}$ there is the decomposition of aromatic compounds present in the scale, such as caffeic acid, in addition to the elimination of water, which is present up to around $175^{\circ} \mathrm{C}$. The component in greatest proportion in the hull is cellulose, which is eliminated between $251^{\circ} \mathrm{C}$ and $358^{\circ} \mathrm{C}$, and corresponds to a weight

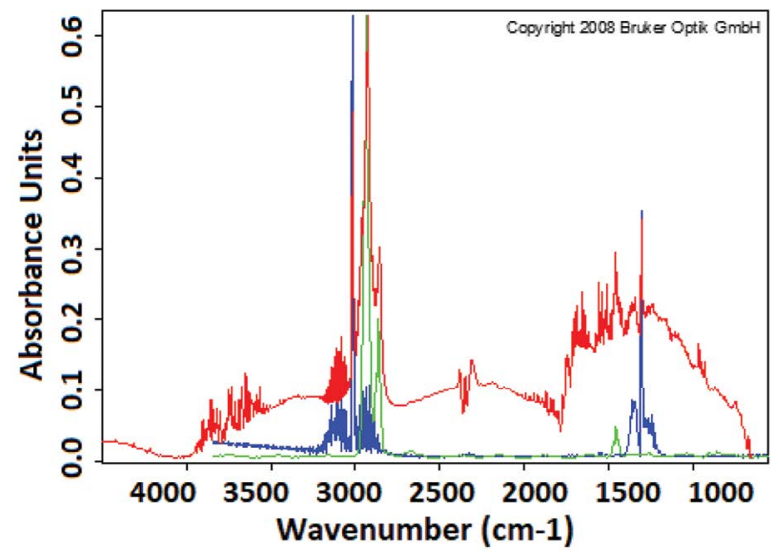

Figure 6. IR spectrum at $472^{\circ} \mathrm{C}-5^{\circ} \mathrm{C} / \mathrm{min}$ (red), spectrum of methane from Bruker data base (blue) and IR spectrum of cyclohexane from Bruker data base too (green).

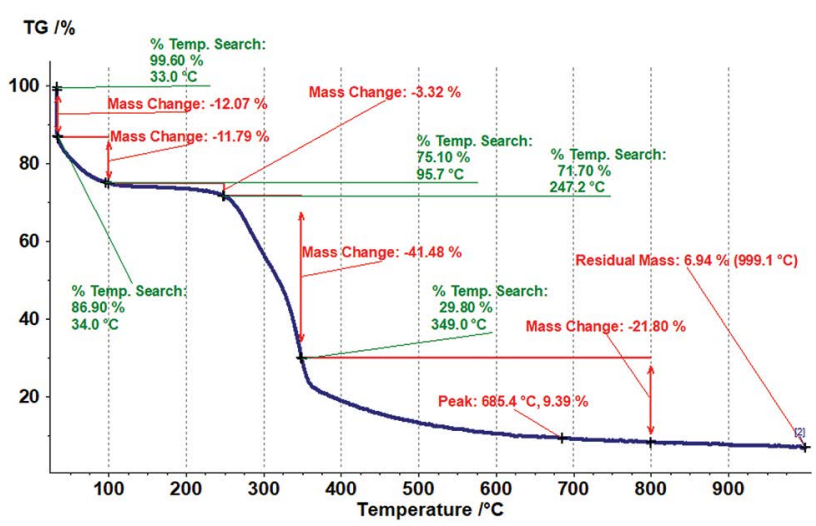

Figure 7. Thermogram (TGA) results for coffee hull samples at $5^{\circ} \mathrm{C} / \mathrm{min}$. loss of approximately $47 \%$. Finally, there is a loss of $16 \%$ between $358^{\circ} \mathrm{C}$ and $800^{\circ} \mathrm{C}$, corresponding to the residual cellulose fragments.

The content of the remaining sample corresponds to minerals equivalent to $6.94 \%$ of the sample. These results are comparable with those of ${ }^{\vartheta}$, previously described.

On the other hand, Figure 8 shows the diagram of the DTGA for the hull, in which it is observed, mainly, a transition in $350^{\circ} \mathrm{C}$, which corresponds to the loss of hemicellulose and cellulose, being they the major components of the coffee hull.

The DSC analysis curve is detailed in Figure 9, for a heating rate of $5^{\circ} \mathrm{C} / \mathrm{min}$. In the curve you can see the different thermal transitions present. The first is related to an endothermic change at $59^{\circ} \mathrm{C}$, linked to the process of dehydration and degradation of some organic compounds of low molecular weight. Subsequently, two exothermic transitions are observed at $311^{\circ} \mathrm{C}$ and $335^{\circ} \mathrm{C}$, due to the degradation of cellulose and hemicellulose. At $481^{\circ} \mathrm{C}$

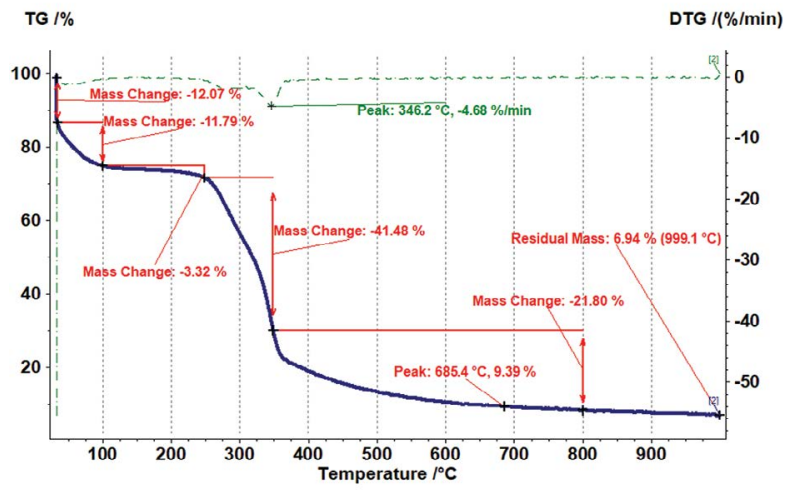

Figure 8. DTGA results for coffee hull samples at $5^{\circ} \mathrm{C} / \mathrm{min}$.

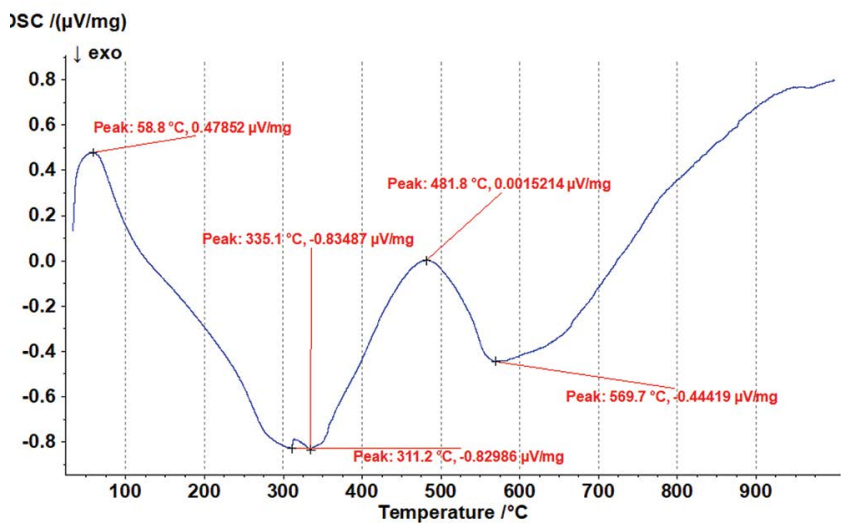

Figure 9. DSC results for coffee hull samples at $5^{\circ} \mathrm{C} / \mathrm{min}$. 
an exothermic transition is detected, which can also be associated with cellulose fractions. Finally, at $570^{\circ} \mathrm{C}$ an exothermic transition is detailed, which corresponds to the carbonization of the remaining cellulose.

\subsection{Drying Curves}

The drying of the grains was carried out in an electric oven, at a controlled temperature of $50 \pm 2^{\circ} \mathrm{C}$. The temperature of the oven and the grains was continuously monitored by means of a Fluke thermographic camera Tis 40 , as indicated in Figure 10. This showed that there were no hot spots and the heating was reasonably uniform.

The grains were distributed in a single layer inside a metal container. The first three samples were taken at 20 minute intervals. The next two samples at intervals of 30 minutes, and the rest of measurements were taken at intervals of one hour. The drying of the grains with

\section{Oven}

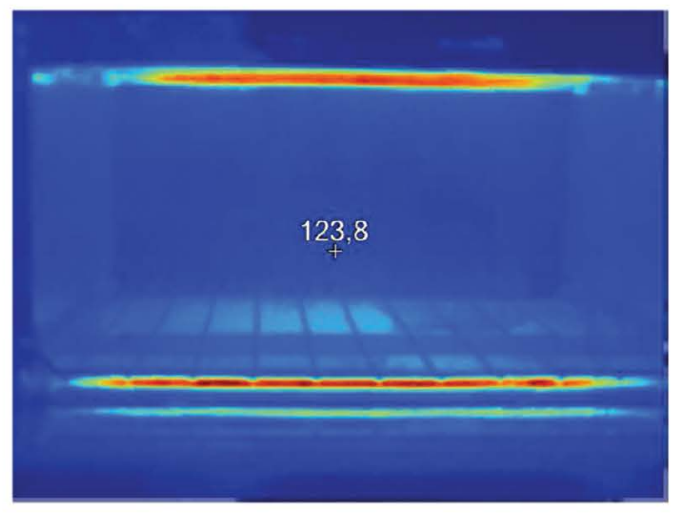

\section{Grain without hull}

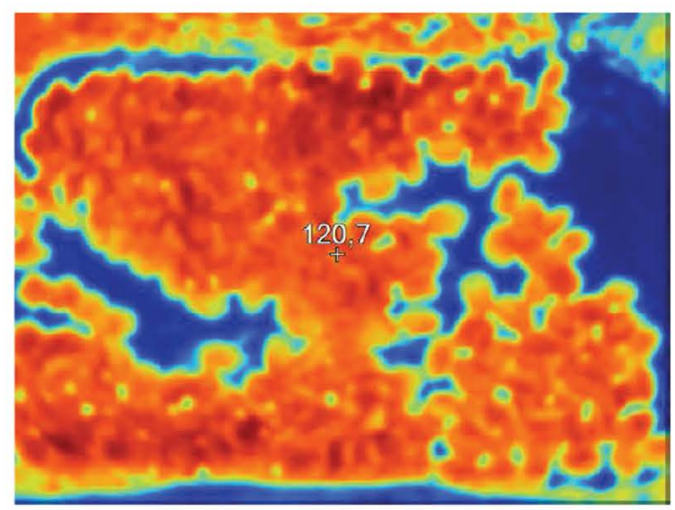

hull took an average of 18.8 hours, while the drying of the grains without hull and of only hull took an average of 10 hours. The calculation of the moisture loss was determined from the loss of mass, according to the following balance:

$$
M_{t}=1-\frac{\left(m_{0}\right) *\left(1-M_{0}\right)}{m_{t}}
$$

where $M_{t}$ is the residual moisture of the grain at time t, $\mathrm{m} 0$ is the initial mass of the grain, $m_{t}$ is the mass of the grain at time $t$, and $M_{0}$ is the initial moisture of the grain, calculated according to Equation (2),

$$
M_{0}=\frac{m_{0}-m_{d}}{m_{0}}
$$

being $m_{d}$ the dry mass of the sample, which was fixed by drying the grains at a temperature of $104^{\circ} \mathrm{C}$ for one hour.

\section{Grain with hull}

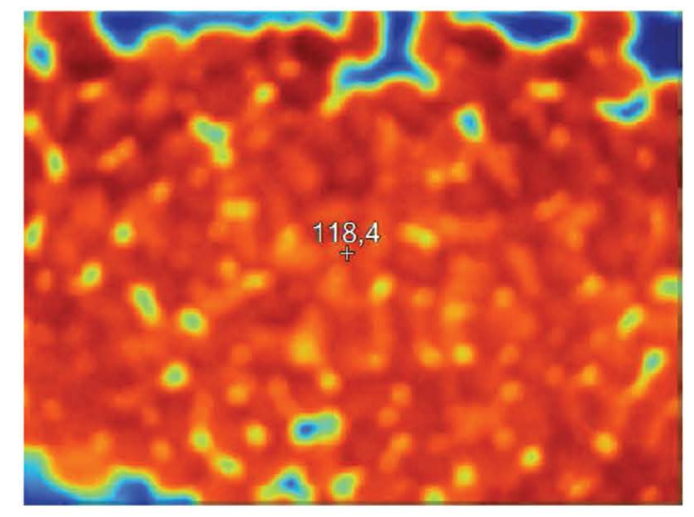

Figure 10. Infrared photographs of following to oven and to samples temperature $\left({ }^{\circ} \mathrm{F}\right)$. 
The dry mass for the samples with shell was calculated at $30.13 \mathrm{~g}$, and for the samples without shell at $31.28 \mathrm{~g}$. The humidity on dry basis was determined with Equation (3),

$$
M=\frac{M_{t}}{1-M_{t}}
$$

Now, we know that the moisture loss in the grain follows Fick's second law ${ }^{17}$, defined in Equation (4),

$$
\frac{d M}{d t}=\nabla \cdot(D \nabla M)
$$

where $\mathrm{D}$ is the effective diffusion coefficient. The solution of this model for a sphere, has form of a summation of exponentials, according to Equation (5):

$$
M R=\frac{M-M_{e}}{M_{0}-M_{e}}=\frac{6}{\pi^{2}} \sum_{n=1}^{\infty} \frac{1}{n^{2}} \exp \left(-D \frac{n^{2} \pi^{2} t}{r^{2}}\right)
$$

where $\mathrm{MR}$ is the dimensionless moisture ratio, $M_{o}$ is the initial moisture in dry basis, $M_{s}$ the equilibrium moisture, also in dry basis, $r$ the sphere radius, and $D$ the effective diffusion coefficient, in square millimeters per minute.

Several authors have used equation (5) to estimate moisture loss in grains, including coffee ${ }^{18-20}$. The solution, of course, is not exact, since the geometry of the grains is ovoid. However, from it can be projected a general solution that has the form of a summation of decreasing exponential terms. This is consistent with the fact that the speed of removal of free moisture in the grains is inversely proportional to the moisture that must be removed. Thus, a more general solution for the Fick equation will have the form of Equation (6):

$$
M R=\frac{M-M_{e}}{M_{o}-M_{e}}=\sum_{i=1}^{\infty} A_{i} \exp \left(-k_{i} * t\right)
$$

From Equation (6) the effective diffusion coefficient can be calculated, dividing the first factor $k_{i=1}$ by $\pi^{2}$ and multiplying it by $\mathrm{r}^{2}$ (the average radius of the grain squared, that for experiments was calculated in $5.5 \mathrm{~mm}$, approximately). From the real data of the drying tests, on samples with shell and without shell, the Nelder-Mead optimization algorithm was used, to determine the diffusion coefficients from the Equation (6), as well as an estimate for $M_{s}$. The data estimated by the model were compared with the real data, using the Root Mean Square Error (rmse) and the coefficient of determination $\gamma^{2}$, according to Equations (7) and (8),

$$
\begin{gathered}
r m s e=\sqrt{\frac{\sum_{1}^{N}\left(M-M^{*}\right)^{2}}{N}} \\
\gamma^{2}=1-\frac{\sum_{1}^{N}\left(M-M^{*}\right)^{2}}{\sum_{1}^{N}(M-\bar{M})^{2}}
\end{gathered}
$$

with $N$ equal to the size of the data set, the actual humidity measured from the experimental data of drying, and $M^{*}$ the humidity calculated from the model.

Next, Tables 1-3 summarize the parameters found for the experiments of drying grains with hull, as well as grains without hull. It is observed that the diffusion coefficients are smaller for the case of the grain with hull since the latter has a remarkable resistance to the passage of water through its structure, (reflected by a relatively high value of its diffusion coefficient). On average it is twice as fast the water transport through the grain without hull relative to the grain with hull. It is also observed that the diffusion coefficient, on average (given the natural variability of the sample), of the hull is 1.2 times greater than the coefficient corresponding to the grain without hull. These results show an obviously delaying effect of the drying process due to the presence of the hull for the defined experimental conditions. This is because

Table 1. Experimental results of coffee grain drying with hull

\begin{tabular}{lllllllll}
\hline & & \multicolumn{9}{c}{$\boldsymbol{D}\left(\mathbf{m m}^{2} /\right.$} \\
TEST & $\boldsymbol{a}_{\boldsymbol{1}}$ & $\boldsymbol{k}_{\boldsymbol{1}}$ & $\boldsymbol{a}_{\mathbf{2}}$ & $\boldsymbol{k}_{\mathbf{2}}$ & $\boldsymbol{m i n})$ & $\boldsymbol{M}_{\boldsymbol{e}}$ & $\boldsymbol{e r m s}$ & $\boldsymbol{\gamma}^{\mathbf{2}}$ \\
\hline 1 & 1.0002 & 0.0013 & 0.0004 & 0.01000 & $\mathbf{0 . 0 0 4 0 0}$ & 0.000200 & 0.0174 & 0.9969 \\
2 & 0.9765 & 0.0017 & 0.0338 & 0.01000 & $\mathbf{0 . 0 0 5 1 4}$ & 0.000100 & 0.0289 & 0.9920 \\
3 & 0.9872 & 0.0024 & 0.0136 & 0.00100 & $\mathbf{0 . 0 0 7 3 6}$ & 0.002067 & 0.0156 & 0.9978 \\
4 & 0.9762 & 0.0023 & 0.0202 & 0.00336 & $\mathbf{0 . 0 0 7 0 5}$ & 0.001680 & 0.0155 & 0.9977 \\
\hline
\end{tabular}


Table 2. Experimental results of coffee grain drying without hull

\begin{tabular}{lllllllll}
\hline TEST & $\boldsymbol{a}_{\boldsymbol{1}}$ & $\boldsymbol{k}_{\boldsymbol{1}}$ & $\boldsymbol{a}_{\mathbf{2}}$ & $\boldsymbol{k}_{\mathbf{2}}$ & $\boldsymbol{D}\left(\mathbf{m m}^{\mathbf{2}} / \mathbf{m i n}\right)$ & $\boldsymbol{M}_{\boldsymbol{e}}$ & $\boldsymbol{e r m s}$ & $\boldsymbol{\gamma}^{\mathbf{2}}$ \\
\hline 1 & 0.97 & 0.0038 & 0.050 & 0.004 & $\mathbf{0 . 0 1 1 6 5}$ & 0.001 & 0.0463 & 0.9821 \\
2 & 0.98 & 0.0037 & 0.034 & 0.004 & $\mathbf{0 . 0 1 1 3 4}$ & 0.006 & 0.0356 & 0.9886 \\
3 & 0.98 & 0.0039 & 0.028 & 0.003 & $\mathbf{0 . 0 1 1 9 5}$ & 0.004 & 0.0312 & 0.9908 \\
4 & 1.00 & 0.0037 & 0.020 & 0.002 & $\mathbf{0 . 0 1 1 3 4}$ & 0.002 & 0.0431 & 0.985 \\
\hline
\end{tabular}

Table 3. Experimental results of hull drying

\begin{tabular}{lllllllll}
\hline TEST & $\boldsymbol{a}_{\boldsymbol{1}}$ & $\boldsymbol{k}_{\boldsymbol{1}}$ & $\boldsymbol{a}_{2}$ & $\boldsymbol{k}_{2}$ & $\boldsymbol{D}\left(\mathbf{m m}^{2} / \mathbf{m i n}\right)$ & $\boldsymbol{M}_{\boldsymbol{e}}$ & $\boldsymbol{e r m s}$ & $\boldsymbol{\gamma}^{2}$ \\
\hline 1 & 0.965 & 0.0043 & 0.0513 & 0.00320 & $\mathbf{0 . 0 1 3 1 8}$ & 0.002 & 0.0918 & 0.9828 \\
2 & 1.001 & 0.0043 & 0.0113 & 0.00432 & $\mathbf{0 . 0 1 3 1 8}$ & 0.002 & 0.0843 & 0.9847 \\
\hline
\end{tabular}

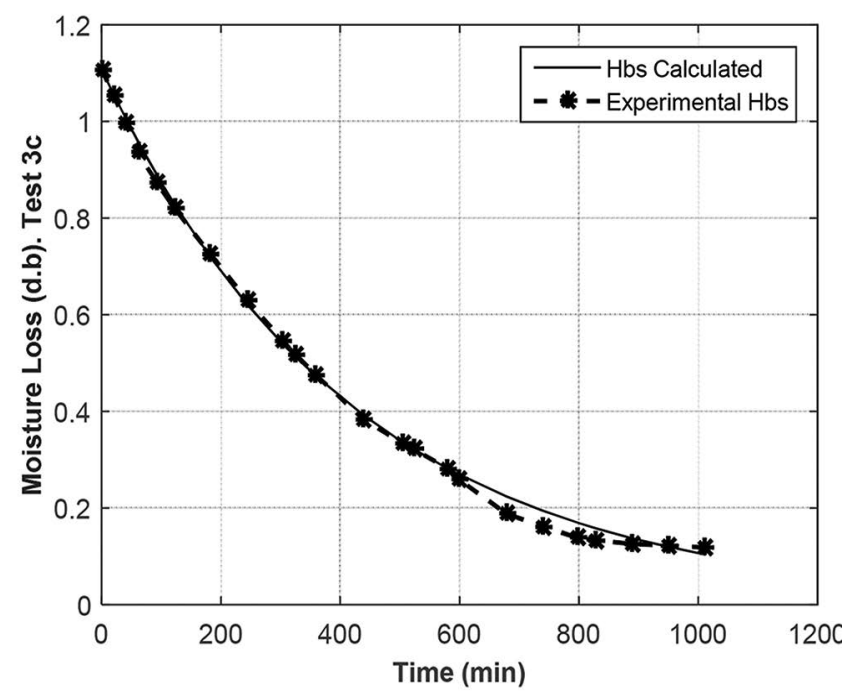

Figure 11. Moisture loss in dry base $(\mathrm{db})$ for a drying experiment of coffee grains with hull.

the hull has a structure and composition of its own that makes the water (liquid/vapor) requires a time to reach its outer surface and then diffuse into the surrounding environment. Figures 11 to 16 show the moisture loss and dimensionless moisture ratio curves, for a drying test of grain with hull (Figures 11 and 12), without hull (Figures 13 and 14), and of only hull (Figures 15 and 16). Figures 17,18 , on the other hand, allow comparing the results for all the experiments carried out.

From the analysis of these experimental results we can affirm that the drying process of both the coffee with hull, the coffee without hull and the hull itself, has a dynamic described by a first order system, with an evident exponential decay.

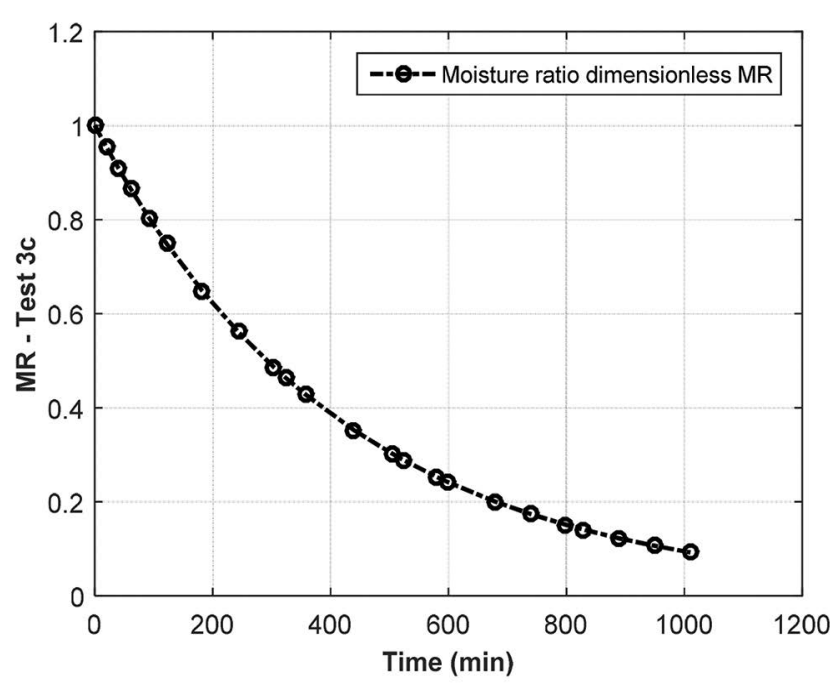

Figure 12. Moisture ratio dimensionless $(\mathrm{db})$ of a drying experiment of coffee grains with hull.

In order to visualize both the dispersion and the symmetry of the results obtained in the drying process, Figures 19 to 22 were made. Since more than 10 experiments were carried out, we can affirm that the quartiles and the outliers of the respective boxes are significant. It can be detailed that the median for the drying of grains without hull (Figure 20), and for the drying of the single hull (Figure 21), is more uniform than for the drying of the grains with hull (Figure 19). The median of the drying experiments of grain without hull is less than the median of the experiments of grain with hull. Similarly, the median for drying experiments with only hull is the least of all the experiments (Figure 21). These results are consistent with the diffusion coefficients 


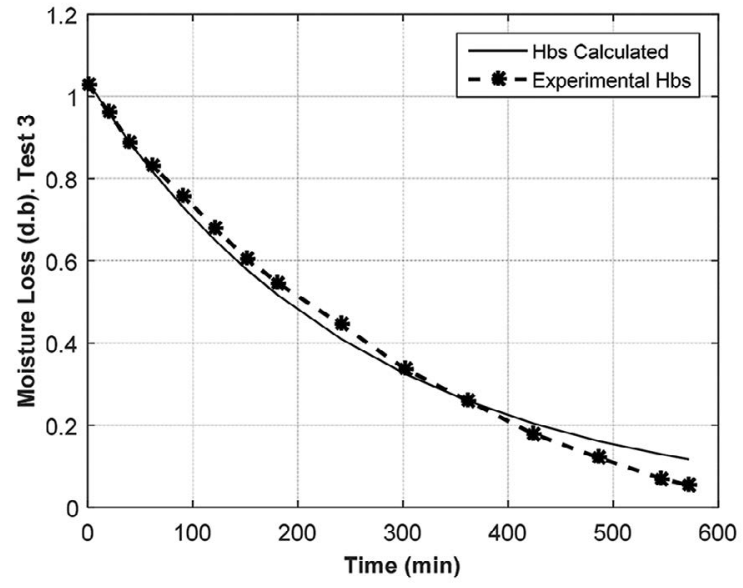

Figure 13. Moisture loss in dry base (db) for a drying experiment of coffee grains without hull.

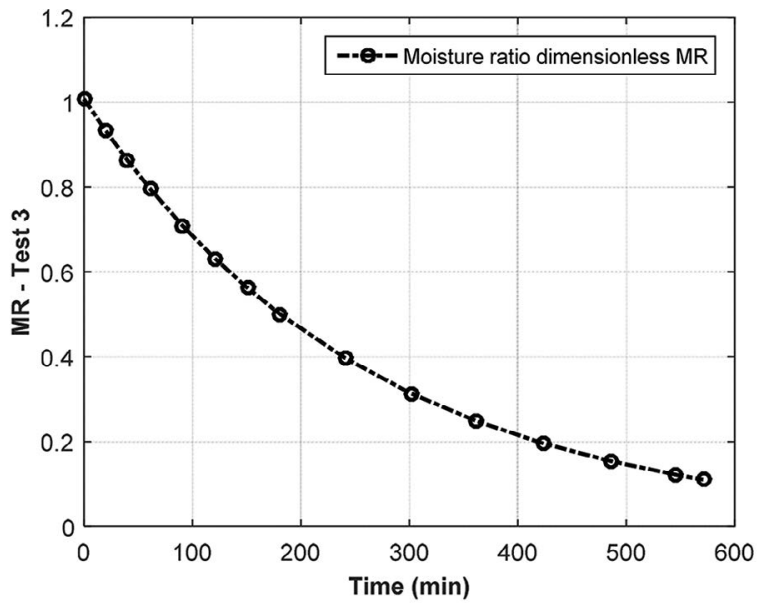

Figure 14. Moisture ratio dimensionless (db) of a drying experiment of coffee grains without hull.

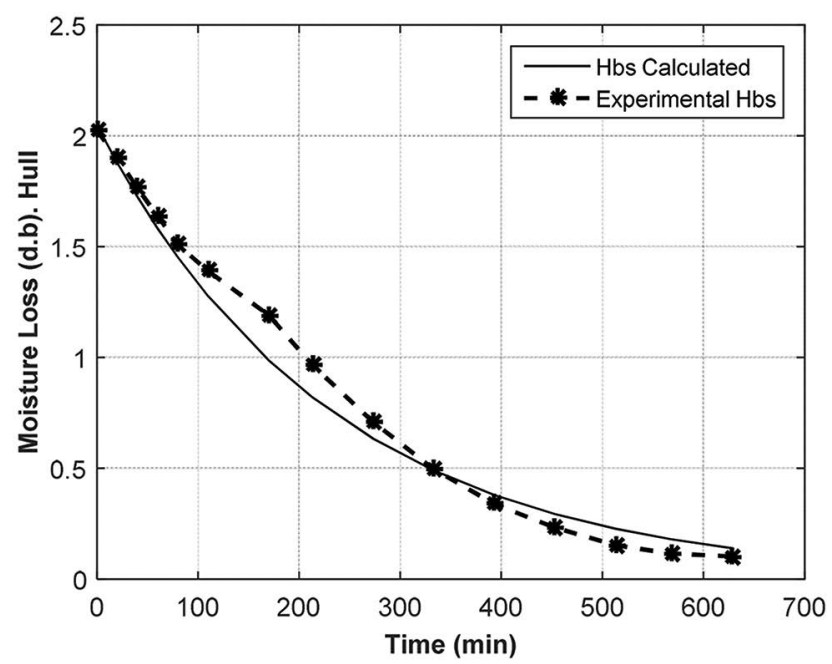

Figure 15. Moisture loss in dry base (db) for a drying experiment of only hull.

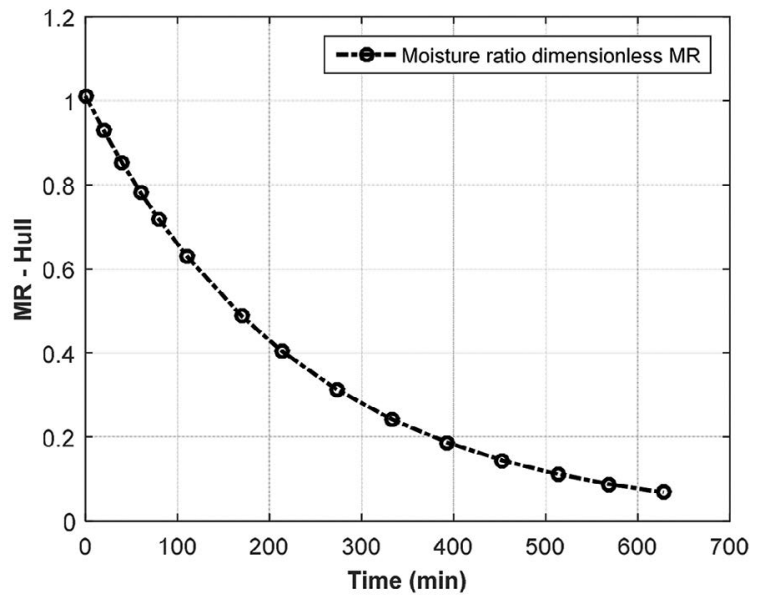

Figure 16. Moisture ratio dimensionless $(\mathrm{db})$ of a drying experiment of only hull.

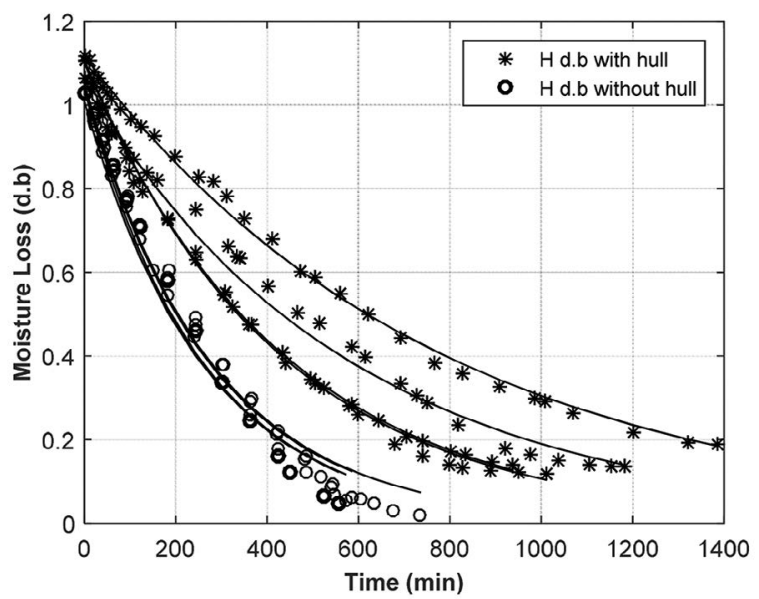

Figure 17. Comparison of moisture loss curves $(\mathrm{db})$ for drying experiments of grains with hull and without hull.

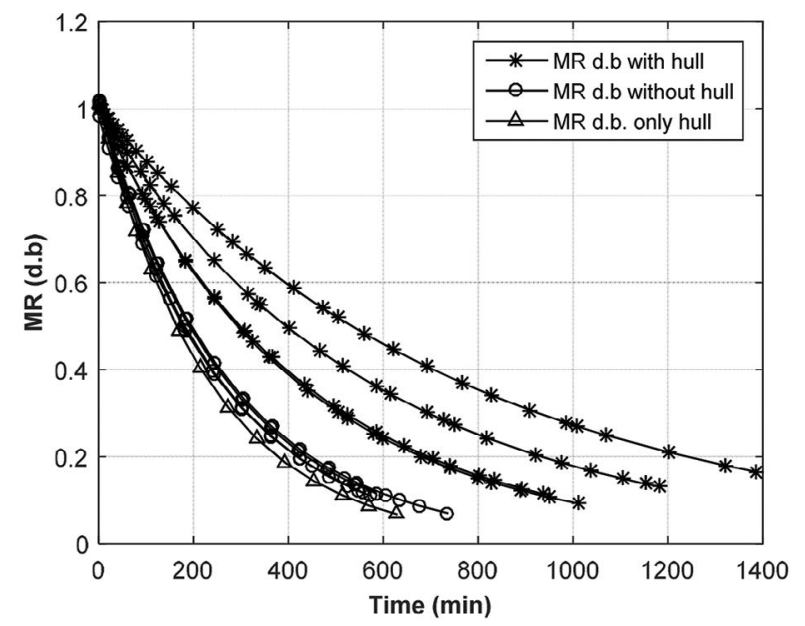

Figure 18. Comparison of moisture ratio dimensionless curves $(\mathrm{db})$ for experiments of drying coffee with hull, without hull and of only hull. 


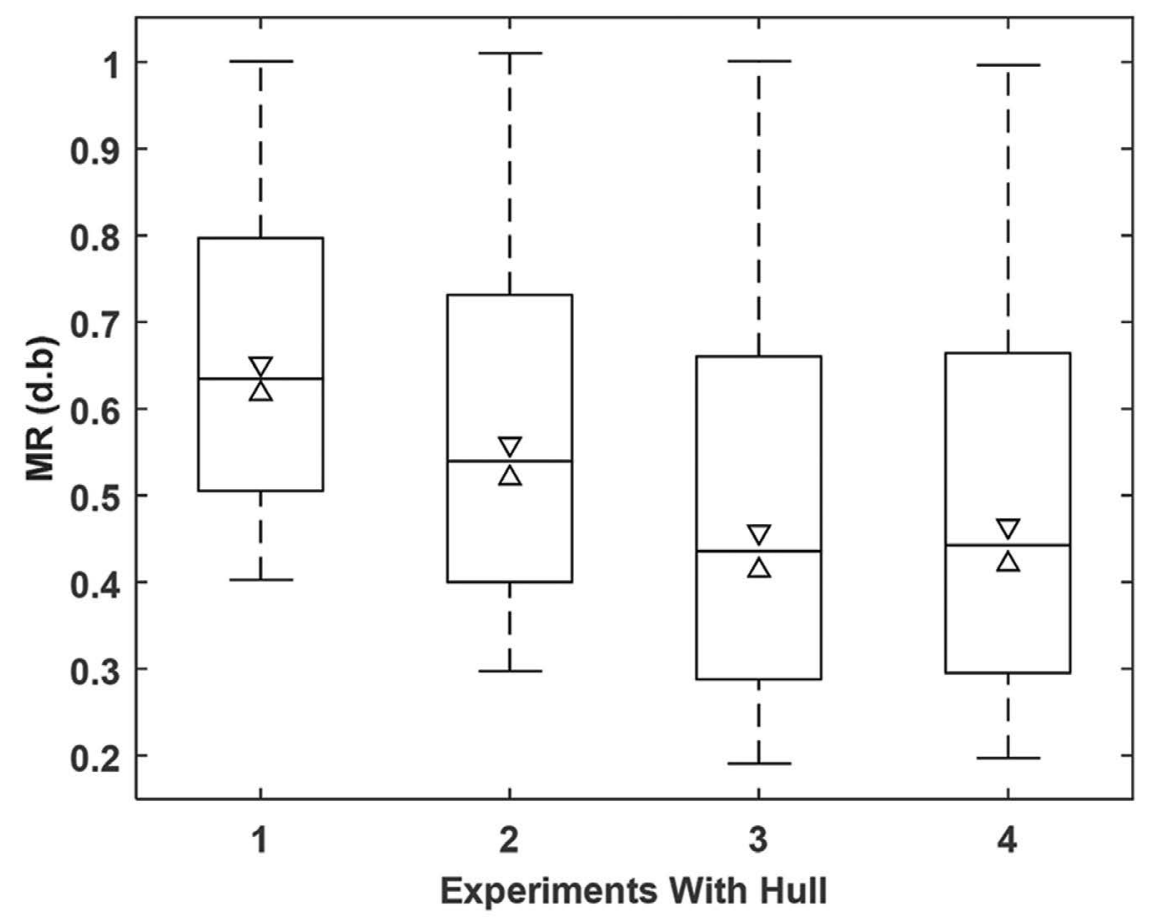

Figure 19. Whiskers diagram of data from moisture ratio dimensionless of coffee grain drying with hull.

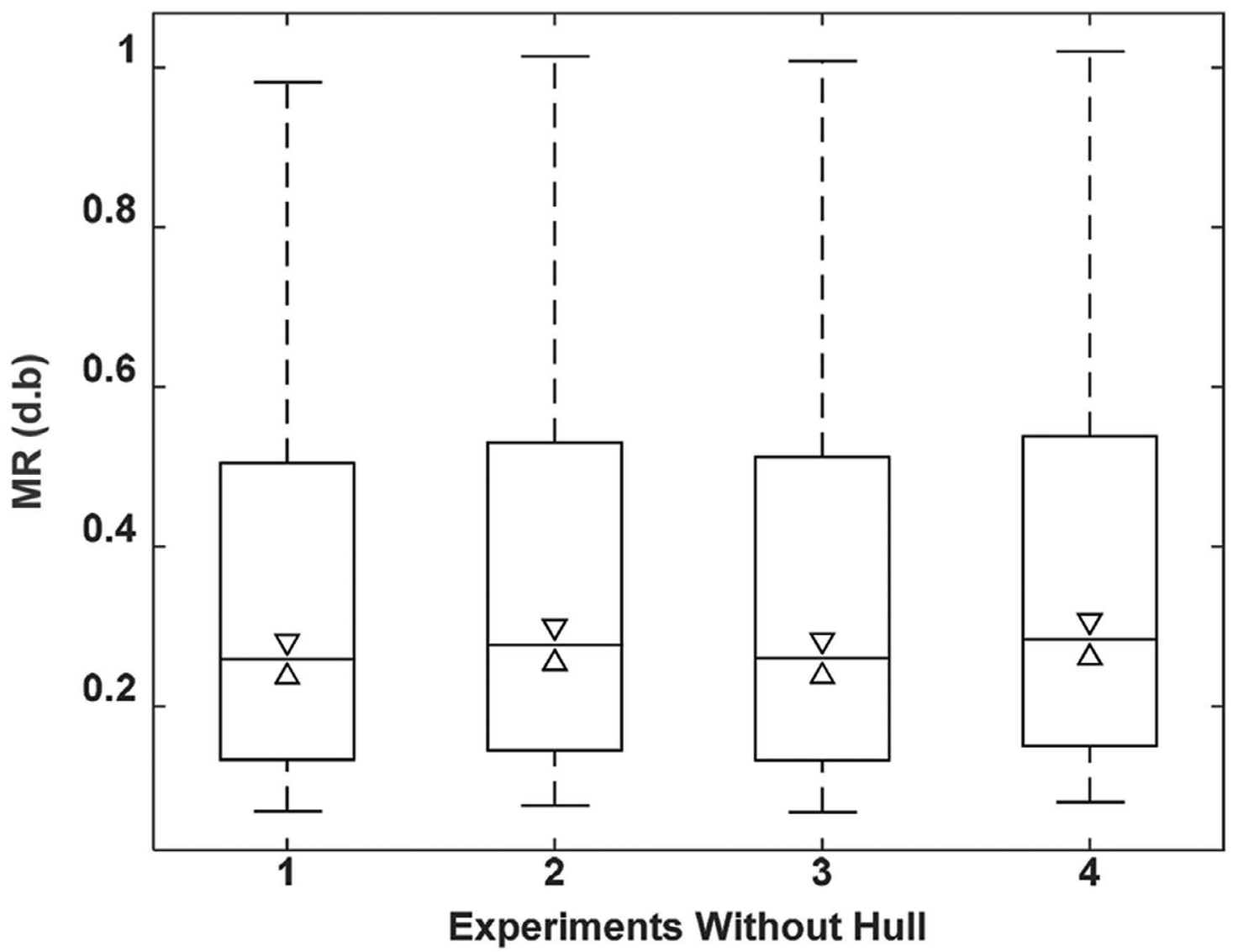

Figure 20. Whiskers diagram of data from moisture ratio dimensionless of coffee grain drying without hull. 


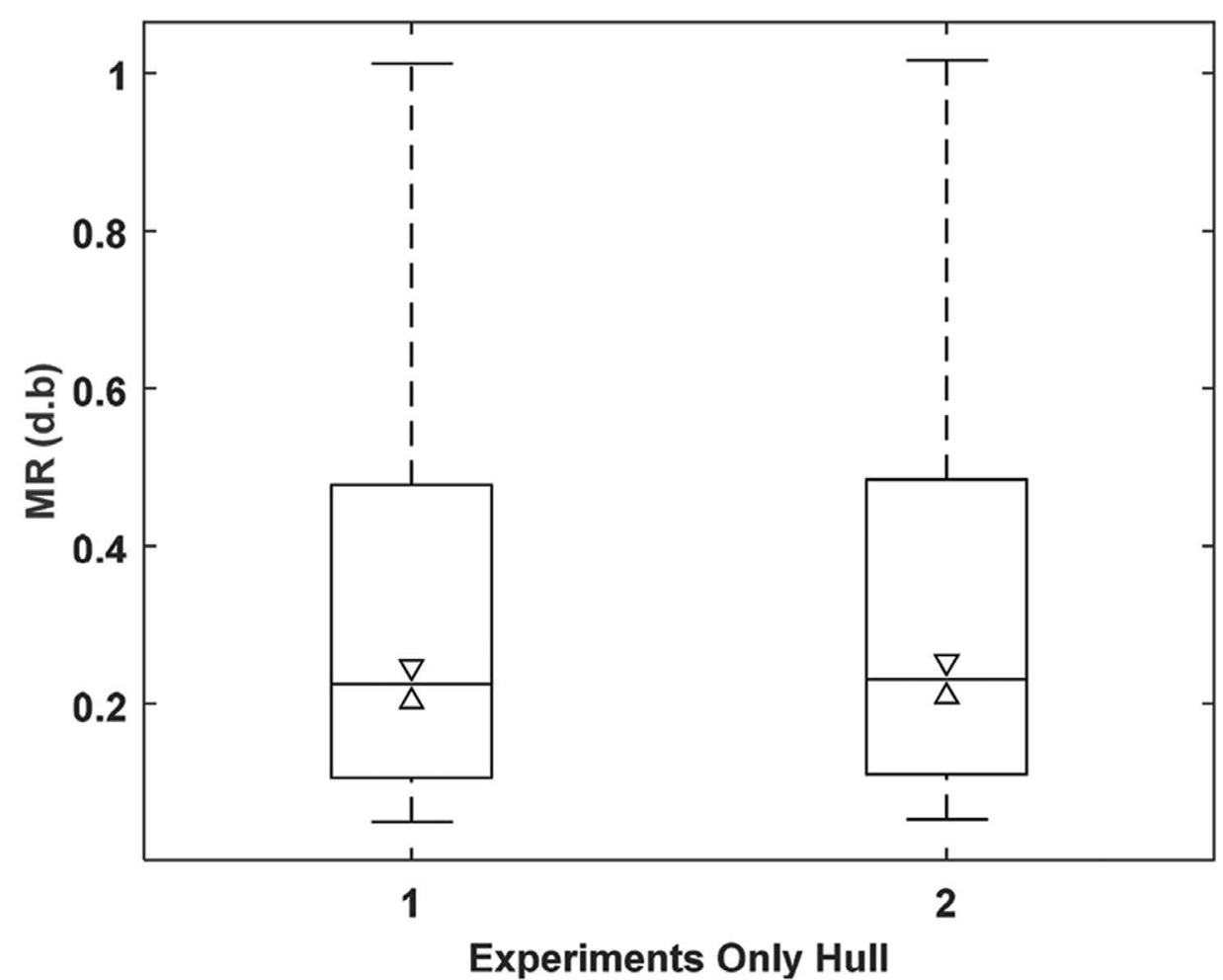

Figure 21. Whiskers diagram of data from moisture ratio dimensionless of hull drying.

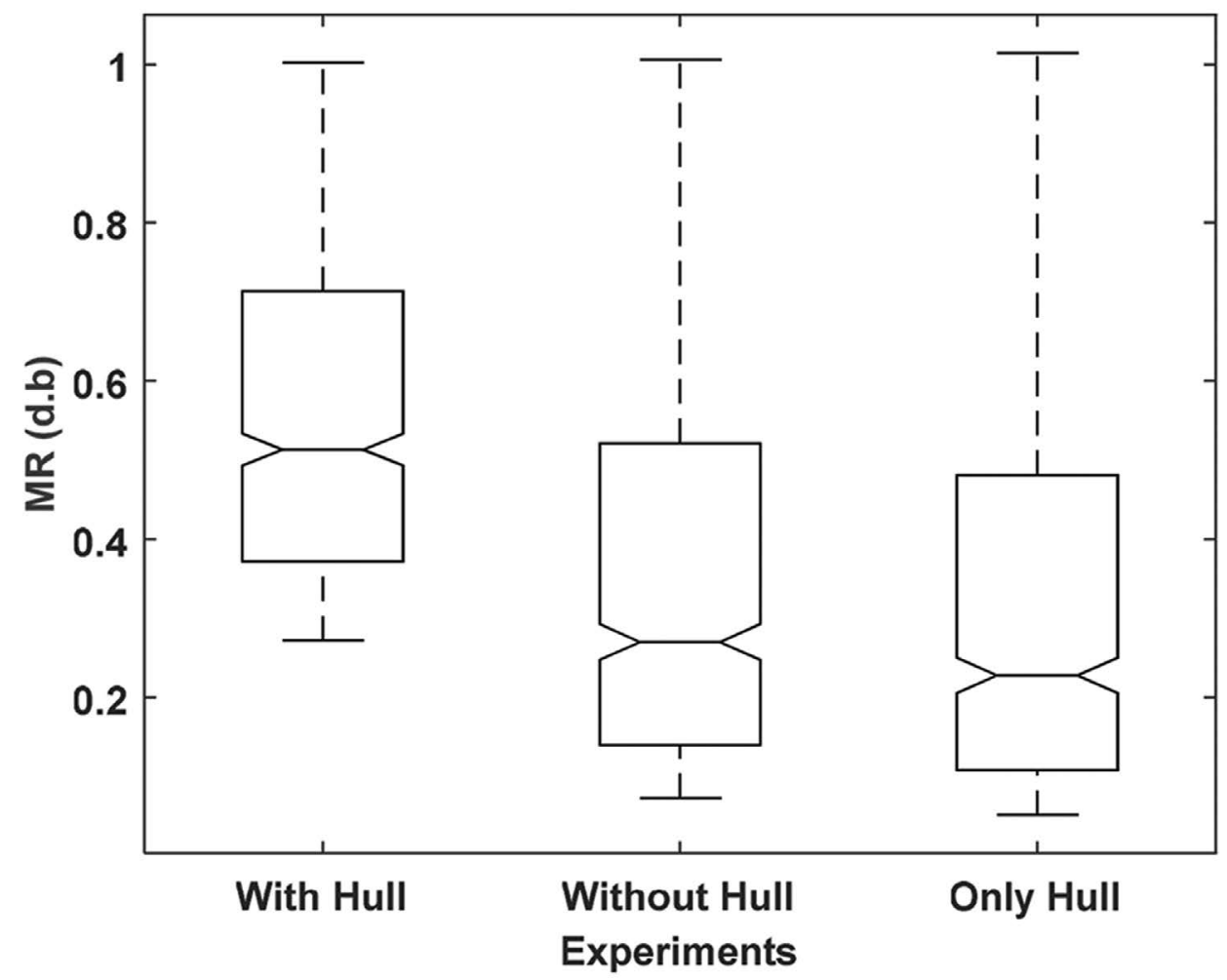

Figure 22. Comparison of whiskers graph from mean data of moisture ratio dimensionless for the three experiments groups. 
found. In all the experiments it is also observed that the distribution of the data is higher than the median, indicating that the loss of humidity is more accelerated at the beginning of the process and decreases rapidly with the passage of time. Figure 22 compiles the statistical analysis for the average drying data, for each of the three types of drying experiments performed.

\section{Conclusions}

In this article we present some of experimental results related to the analysis of IR, DSC, TGA and DTGA of the coffee hull. The samples of coffee beans corresponded to the variety Castilla and cultivated in northeastern Colombia. Likewise, drying curves were included for grain samples with hull, without hull and for the single hull. The respective water diffusion coefficients in each of these samples are also reported.The diffusion coefficient for the hull is greater than that of the coffee bean alone, obviously foreseeing that it will affect the drying process since the humidity will take longer to pass through. In addition, it was found that the basic constituents of the hull are cellulosic based. This aspect is believed to be one of those responsible for the delay effect in the drying of the shell peel that was observed. A first implication of these results is the need to remove the hull by mechanical means without increasing the operational conditions during its drying process.

\section{References}

1. Murthy P, Naidu M. Sustainable management of coffee industry by-products and value addition- A review. Resources, Conservation and recycling. 2012; 66:45-58. https://doi.org/10.1016/j.resconrec.2012.06.005

2. Didanna H. A critical review on feed value of coffee waste for livestock feeding. World Journal of Biology and Medical Sciences. 2014; 2(5):72-86.

3. Braham J, Bressani, R. Coffee pulp: Composition, technology, and utilization. Ottawa, ON, CA: IDRC; 1979.

4. Rathinavelu R, Graziosi G. Potential alternative use of coffee wastes and by-products. Coffee Organization; 2005. p. 1-5.

5. Rodríguez N, Zambrano DA. Los subproductos del café: fuente de energía renovable. Avances Técnicos CENICAFÉ. 2013; 393:1-8.
6. Esquivel P, Jiménez VM. Functional properties of coffee and coffee by-products. Food Research International. 2012; 46(2):488-95. https://doi.org/10.1016/j.foodres.2011.05.028

7. Bekalo SA, Reinhardt HW. Fibers of coffee husk and hulls for the production of particleboard. Materials and structures. 2010; 43(8):1049-60. https://doi.org/10.1617/s11527-009-9565-0.

8. Abarca D, Martínez R, Mu-oz JJ, Torres MP, Vargas G. Residuos de café, cacao y cladodio de tuna: Fuentes promisorias de fibra dietaria. Revista Tecnológica-ESPOL. 2010; 23(2):63-9.

9. Manals E, Penedo M, Giralt G. Análisis termogravimetrico y térmico diferencial de diferentes biomasas vegetales. Tecnología Química. 2011; 31(2):180-90.

10. Reis Orsini R, Moscardini Filho E, Mercuri LP, do Rosário Matos J, Carvalho F. Thermoanalytical study of inner and outer residue of coffee harvest. Journal of Thermal Analysis and Calorimetry. 2011; 106(3):741-5. https://doi. org/10.1007/s10973-011-1542-5

11. Mhilu CF, Mashingo PP. Thermal degradation characteristics of blends of Tanzanian Bituminous coal and coffee husks. 2nd International Conference on Advances in Engineering and Technology (AET2011); 2011. p. 1-5.

12. Rodríguez MH, Yperman J, Carleer R, Maggen J, Daddi D, Gryglewicz G, Calvis AO. Adsorption of Ni (II) on spent coffee and coffee husk based activated carbon. Journal of Environmental Chemical Engineering. 2018; 6(1):1161-70. https://doi.org/10.1016/j.jece.2017.12.045

13. Huang L, Mu B, Yi X, Li S, Wang Q. Sustainable use of coffee husks for reinforcing polyethylene composites. Journal of Polymers and the Environment. 2018; 26(1):48-58. https://doi.org/10.1007/s10924-016-0917-x

14. Collazo-Bigliardi S, Ortega-Toro R, Boix AC. Isolation and characterisation of microcrystalline cellulose and cellulose nanocrystals from coffee husk and comparative study with rice husk. Carbohydrate Polymers. 2018; 191:205-15. https://doi.org/10.1016/j.carbpol.2018.03.022 PMid:29661311

15. de Carvalho Oliveira F, Srinivas K, Helms G, Isern N, Cort J, Gonçalves A, Ahring, B. Characterization of coffee (Coffea arabica) husk lignin and degradation products obtained after oxygen and alkali addition. Bioresource technology. 2018; 257:172-80. https://doi.org/10.1016/j. biortech.2018.01.041 PMid:29500951

16. Lubwama $M$, Yiga VA. Characteristics of briquettes developed from rice and coffee husks for domestic cooking applications in Uganda. Renewable 
Energy. 2018; 118:43-55. https://doi.org/10.1016/j. renene.2017.11.003

17. Crank J. The mathematics of diffusion. 2nd ed. Oxford University Press; 1975. p. 1-421.

18. Sharma A, Kunze O, Tolley H. Rough rice drying as a two-compartment model. Transactions of the ASAE. 1982;25(1):221-4. https://doi. org/10.13031/2013.33508
19. Varadharaju N, Karunanidhi C, Kailappan R. Coffee cherry drying: a two-layer model. Drying Technology. 2001; 19(3-4):709-15. https://doi.org/10.1081/DRT-100103947

20. Corrêa P, Horta de Oliveira G, Lelis A, Mendes F, Duarte A. Thermodynamic properties of drying process and water absorption of rice grains. CyTA-Journal of Food. 2017; 15(2):204-10. https://doi.org/10.1080/19476337.2016.1238012 